\title{
Fuzzy logic control of wind turbine storage system connected to the grid using multilevel inverter
}

\author{
Ali Berboucha, Kamel Djermouni, Kaci Ghedamsi, Djamal Aouzellag \\ Laboratoire de Maitrise des Énergies Renouvelables, Faculté de Technologie, University of Bejaia. Algeria \\ b.ali06@hotmail.fr
}

\begin{abstract}
This paper aimed to evaluate the use of wind turbine storage systems to provide electricity in the electrical grid through a five-level inverter. The proposed system is composed of four wind turbine generators based on permanent magnet synchronous generator (PMSG), four battery storage systems connected to each capacitor of the DC link and a five level diode clamped inverter connected to the grid by three phase transformer. The control algorithm proposed is based on fuzzy logic to tracks and extract the maximum wind power by controlling the rotational speed of wind turbine, which is most appropriate when there is a lack of information on the characteristic $C_{p}(\lambda, \beta)$ of the turbine. The system operator controls the power production of the four wind turbine generators by sending out reference power signals to each input side regulation unit, the input side regulation units regulate the voltage of each capacitor of the DC link, regulate the voltage and the state of charge of each battery storage system. The inverter is controlled by simplified space vector modulation which allows us to reduce the computational time and reduce the algorithm complexity compared to the conventional five levels space vector modulation, the grid side control level regulate the power and the current injected to the grid.
\end{abstract}

Keywords: Wind turbine generator, Battery storage, Five level diode clamped inverter, Simplified space vector modulation, Supervision and management, Fuzzy logic controller.

Received: 15/02/2017 - Accepted: 16/03/2017

\section{Introduction}

The use of wind energy conversion systems has been considerably expanded over the last few decades, the installed wind turbines can be classified according to two categories: wind turbines with fixed speed and with variable speed, recently variable speed wind turbine generators are largely used, the authors in [1-2] gave some advantages of this kind of wind turbines compared to the fixed speed. One of the problems associated with variable-speed wind systems today is the presence of the gearbox coupling the wind turbine to the generator [2], permanent magnet synchronous generators ( $P M S G)$ turns out to be more and more attractive due to the low rotational speed and gearbox can be removed [3], this is important not only due to less space need, but also for reducing the downtime failure and because the gearbox usually requires significant maintenance [4], other advantages of PMSG are cited in [5]. Many controllers to track the maximum power available in the wind have been developed in literatures [1-8], the authors in $[4,8]$ gave some advantages and disadvantages for each technique, in the case where the turbine parameters and the conditions climatic are unknown, the application of $M P P T$ based fuzzy logic is most suitable. Energy storage systems (ESSs) have some important applications in operations like grid stabilization, stable power quality and reliability management, load shifting, grid operational support, smooth power injection to the grid. Several power smoothing methods have been introduced in literature [9-16], battery energy storage system (BESS) is selected as an energy storage medium and incorporated into wind farms for dispatching the wind power, it is usually necessary to maintain the power and energy balance as well as to improve the power quality [17]. Recently multilevel inverters appear to be a very good solution for renewable energy applications, various types of topologies are presented in the literature [18, 19]. The diode clamped inverter topology appears to be more attractive for the reason cited in [19]. Different methods of modulation techniques exist to control the inverter they are developed in [18-21]. In this paper as shown in Fig.1 fuzzy logic MPPT associated to variable speed wind turbine battery storage system connected to the grid with a five level diode clamped inverter is presented, each turbine is connected to each capacitor of the $D C$ link of the inverter via an $A C / D C$ converter and for each of this capacitor of the $D C$ link a battery bank is also connected, the inverter is controlled by a simplified space vector modulation and its output is connected to the network via a perfect transformer. The proposed structure has many advantages over classic systems, in the case where the two levels converter is used to connect 
production source to the grid, limits for power rise are imposed. The five level diode clamped inverter does not have this problem because it has a $D C$ bus segmented by four series connected capacitors, so it offers many connection possibilities. In addition, harmonic distortion filter elements and cost of installation are reduced; moreover the proposed structure offers the advantage balancing the voltages across each capacitor without using complex algorithm.

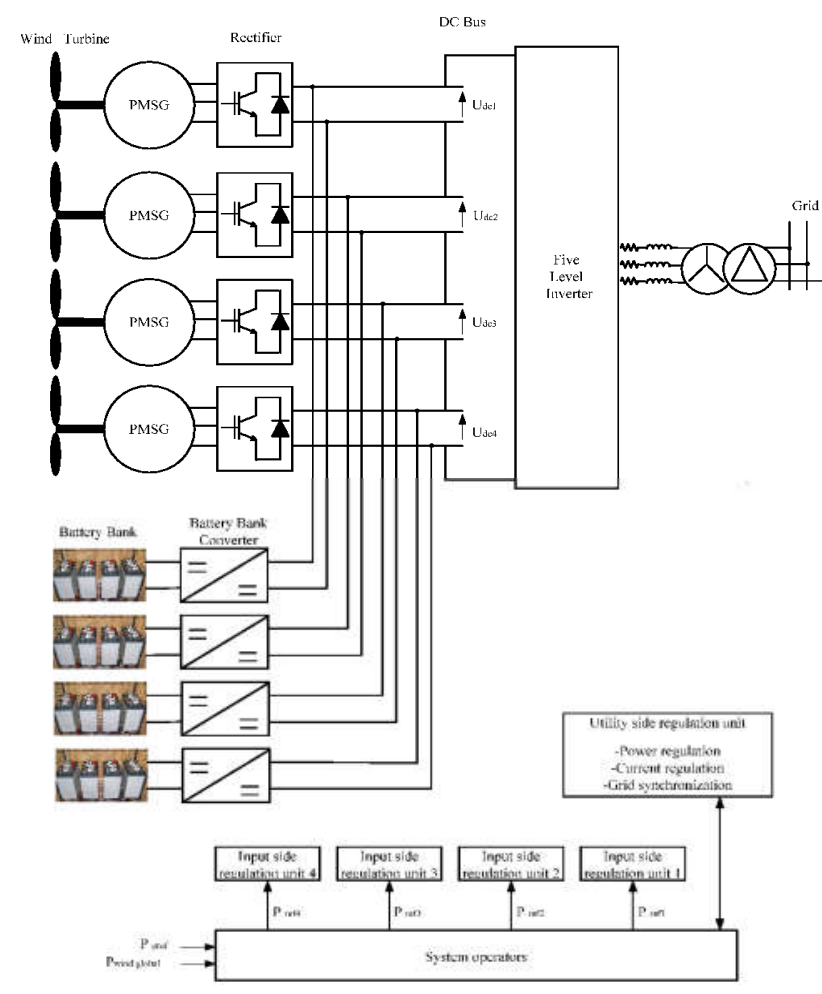

Figure 1. Global wind turbine connection system

\section{Modeling of Wind Energy Conversion System}

\section{II.1. Modelling of wind turbine}

The aerodynamics of the wind turbine can be characterized by its $C_{p}(\lambda, \beta)$ curve, which is usually provided by the manufacturers. $C_{p}$ is the power coefficient; it corresponds to maximum mechanical power extraction from wind at its maximum value and is a function of the tip-speed ratio $\lambda$ and the pitch angle $\beta$. For a given $C_{p}$, the mechanical power $P_{m}$ and mechanical torque $T_{e m}$ extracted from the wind by the wind turbine can be given by [1]:

$$
\begin{gathered}
P_{m}=0.5 \rho S C_{p}(\lambda, \beta) V^{3}{ }_{w} \\
T_{e m}=\frac{p_{m}}{\Omega_{m}}
\end{gathered}
$$

Power coefficient is a function of the blade pitch angle, and the linear relation between the wind speed and the speed of the blade tip. This coefficient indicates the efficiency that the wind turbine transforms the kinetic energy contained in wind into mechanical energy. According to the Betz limit, for horizontal axis turbines with three blades, the maximum possible value is approximately 0.593. In Fig. 2 is presented some power coefficient curves for different pitch angles. The best result is with the angle in zero degrees.

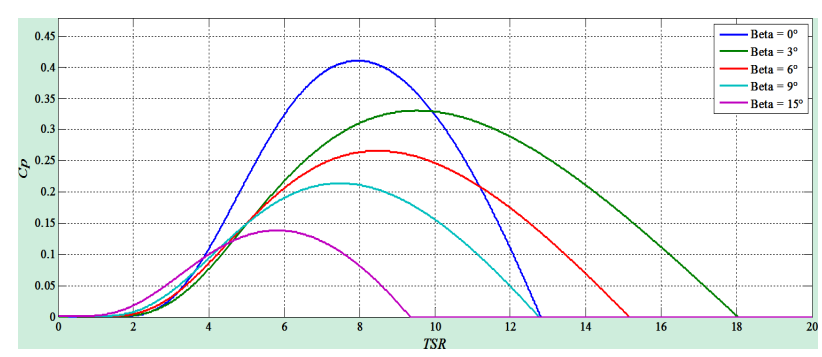

Figure 2. $C_{p}-\lambda$ curves for different pitch angles

\section{II.2. Modelling of PMSG}

The generator chosen for the conversion of wind energy is the $P M S G$; the dynamic model of $P M S G$ in $d-q$ frame can be represented by the following equations:

$$
\left(\begin{array}{l}
V_{s d} \\
V_{s q}
\end{array}\right)=R_{s}\left(\begin{array}{l}
i_{s d} \\
i_{s q}
\end{array}\right)+\frac{d}{d t}\left(\begin{array}{l}
\lambda_{s d} \\
\lambda_{s q}
\end{array}\right)+\omega_{s}\left(\begin{array}{cc}
-1 & 0 \\
0 & 1
\end{array}\right)\left(\begin{array}{c}
\lambda_{s q} \\
\lambda_{s d}
\end{array}\right)
$$

Where $V_{s d}, V_{s q}$, are the $d, q$ axis stator voltages; $i_{s d}, i_{s q}$, are the $d, q$ axis stator currents; $R_{s}$ is the stator resistance; $\lambda_{s d}$, and $\lambda_{s q}$ are the $d, q$ axis stator flux linkages. The equations for these values in the absence of damper circuits can be expressed in terms of the stator currents and the magnetic flux as following [4]:

$$
\begin{gathered}
\left(\begin{array}{c}
\lambda_{s d} \\
\lambda_{s q}
\end{array}\right)=\left(\begin{array}{cc}
L_{d s} & 0 \\
0 & L_{q s}
\end{array}\right)\left(\begin{array}{l}
i_{s d} \\
i_{s q}
\end{array}\right)+\left(\begin{array}{l}
\Psi_{f} \\
0
\end{array}\right) \\
\omega_{s}=P \Omega_{r}
\end{gathered}
$$

$L_{d s}$ and $L_{q s}$, are the $d, q$ axis stator inductances; $\Psi_{f}$ is the magnetic flux; $\omega_{s}$ is the generator electrical angular speed; $\Omega_{r}$ the mechanical angular speed and $P$ is the pair number of poles. Electromagnetic torque is given as:

$$
T_{e m}=\frac{3}{2} P\left(\lambda_{s d} i_{s q}-\lambda_{s q} i_{s d}\right)
$$

\section{II.3. Battery bank model}

A lead acid $(L A)$ batteries is the first and the oldest type of rechargeable battery in existence, they are invented in 1859 and they operate using a liquid electrolyte [22]; they are used in some areas because of their uncomplicated and fabrication costs are low, they are cheap $(\$ 300-600 / k W h)$, highly reliable, improved maturity level in the technology, highly efficient $(70$ $90 \%$ ) [22], extended service life of around 5 years or 
$250-1000$ charge/discharge cycles and a quick response especially in automobile systems and applications where weight is not seen as a parameter for the conditions of use. In Renewable Energy System applications multiple deep-cycle lead-acid (DCLA) batteries, which provide a stable current for a large time period, are connected to form a battery bank. Indeed, banks of up to $1 M W$ of lead-acid batteries are already being used to stabilize wind farm power generation. For instance, DCLA are designed for backup and peak shifting in off-grid and grid-tied $P V$ systems [23]. Lead acid batteries are used to ensure several hours to several days of energy storage. The model representation of the lead-acid battery is shown in Fig. 3. The capacity of the battery is determined by integrating the main reaction current $I_{M R}$.

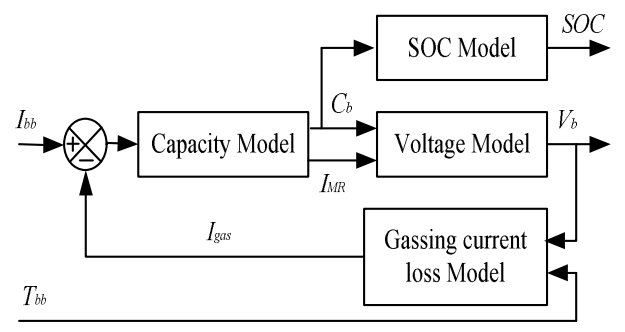

Figure 3. General structure of battery model

To take into account losses gassing increased during the recharging of the battery at high voltage and temperature, in our case it is represented by the loss-current $I_{\text {gas }}$, represents a significant improvement compared to battery models for the simulation of hybrid energy systems. The main reaction current of the battery bank can be expressed as:

$$
I_{M R}(t)=I_{b b}(t)-I_{g a s}(t)
$$

Where $I_{M R}$ is the main battery reaction current $(A), I_{b b}$ is external battery current $(A)$, and $I_{\text {gas }}$ is battery gassing current (A). The actual battery capacity can be determined as:

$$
C_{b}(t)=\int_{0}^{t} I_{M R}(t) d t+C_{b 1}
$$

Where $C_{b}$ is the actual battery capacity $(A h)$ and $C_{b l}$ is Initial battery capacity $(A h)$. The state-of-charge can be calculated by referring the actual capacity to the rated capacity of the battery:

$$
\operatorname{SOC}(t)=\frac{C_{b}(t)}{C_{b 1}} 100(\%)
$$

For all calculations shown, different model parameters represent the characteristic voltage behavior of lead-acid batteries when charging or discharging. The internal battery voltage is calculated as [24]:

1) Charging $\left(I_{b b}<0\right): E_{b}(t)=E_{0, c}+A_{c} \cdot X(t)+$

$$
\frac{C_{c} X(t)}{\left(D_{c}-X(t)\right)^{E F C}}
$$

2) Discharging $\left(I_{b b}>0\right): E_{b}(t)=E_{0, d}+A_{d} \cdot X(t)+$

$$
\frac{C_{d} X(t)}{\left(D_{d}-X(t)\right)^{E F d}}
$$

Where $E_{b}$ is the internal battery voltage $(V)$, and $X$ is normalized maximum charge/discharge capacity $(A h)$, it is given as:

Charging $\left(I_{b b}<0\right)$

$X(t)=\frac{Q_{\max . c}}{Q_{\max .}\left(I_{M R}(t)\right)} C_{b}(t)$

Discharging $\left(I_{b b}>0\right)$

$$
X(t)=\frac{Q_{\max . d}}{Q_{\max .}\left(I_{M R}(t)\right)}\left(Q_{\max . d}-C_{b}(t)\right)
$$

The maximum capacity $Q_{\max }$ in dependence of the main reaction current of the battery is expressed by a third order polynomial equation, where the parameters have to be determined by empirical curve fitting from measured data [24]:

Charging $\left(I_{b b}<0\right)$ :

$$
Q_{\max }\left(I_{M R}(t)\right)=C_{1}\left[I_{M R}(t)\right]^{3}+C_{2}\left[I_{M R}(t)\right]^{2}+C_{3} I_{M R}(t)+C_{4}
$$

Discharging $\left(I_{b b}>0\right)$ :

$$
Q_{\max }\left(I_{M R}(t)\right)=D_{1}\left[I_{M R}(t)\right]^{3}+D_{2}\left[I_{M R}(t)\right]^{2}+D_{3} I_{M R}(t)+D_{4}
$$

Therefore, the battery terminal voltage $V_{b}$ can be calculated as:

Charging $\left(I_{b b}<0\right): V_{b}(t)=E_{b}(t)-R_{0 c} I_{M R}(t)$

Discharging $\left(I_{b b}>0\right): V_{b}(t)=E_{b}(t)-R_{0 d} I_{M R}(t)$

The voltage of a string of batteries is given by multiplying the battery voltage with the number of $12 \mathrm{~V}$ batteries in series: $V_{b b}(t)=V_{b}(t) . B_{s}$

Where $V_{b b}$ is the voltage of battery bank $(V)$, and $B_{s}$ is number of $12 \mathrm{~V}$ batteries in series.

\section{II.4. Multilevel inverter model}

First's studies on multilevel inverters have been made with three-level inverter that has been presented by Nabae [18]. Last few years, multilevel inverters have gained lot of attention in the field of medium voltage and high power application due to their many advantages cited in [19], recent applications of this kind of inverters have a variety including induction machine and motor drives, active filters, interface of renewable energy sources, flexible $A C$ transmission systems and static compensators[18, 19]. Diode clamped inverters, especially three-level structure, have a wide use in motor drive applications compared with other multilevel inverter topologies; but when the number of level exceeds three, there is a limitation on number of clamping diodes and complexity to control the inverter. In this paper five level diode clamped inverter topology is used, as we can see in Fig. 4 circuit diagram of this topology is presented. 
The inverter has three legs; each leg is composed of eight switches with anti parallel diodes, capacitors split the $D C$-bus voltage. Voltage across each capacitor is $U_{d c} / 4$, and voltage stress across each switching device is limited to $U_{d c} / 4$ through the clamping diodes. Using the complementary control between upper switches and lower ones, so to have:

$$
\left\{\begin{array}{l}
S_{k 1}=1-S_{k 5} \\
S_{k 2}=1-S_{k 6} \\
S_{k 3}=1-S_{k 7} \\
S_{k 4}=1-S_{k 8}
\end{array}\right.
$$

Where $k=(1,2,3)$ is the leg number. Assuming ideal power switches, connection functions are defined as follows:

$$
\left\{\begin{array}{l}
G_{k 1}^{a}=S_{k 1} \cdot S_{k 2} \cdot S_{k 3} \cdot S_{k 4} \\
G_{k 2}^{a}=S_{k 5} \cdot S_{k 6} \cdot S_{k 7} \cdot S_{k 8} \\
G_{k 1}^{b}=\left(1-S_{k 1}\right) S_{k 2} \cdot S_{k 3} \cdot S_{k 4} \\
G_{k 2}^{b}=S_{k 5} \cdot S_{k 6} \cdot S_{k 7} \cdot\left(1-S_{k 8}\right)
\end{array}\right.
$$

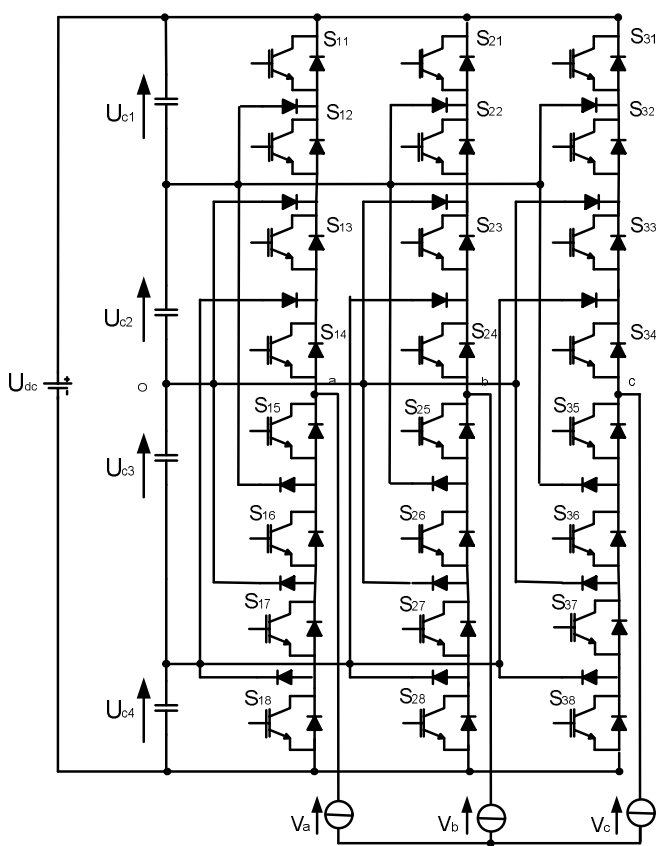

Figure 4. Circuit diagram of five level diode clamped inverter

Voltage of leg $k(k=1,2,3)$ of five-level inverter relative to middle point $O$ is given by the following equation:

$$
\left\{V_{k o}=\left[2\left(G_{k 1}^{a}-G_{k 2}^{a}\right)+\left(G_{k 1}^{b}-G_{k 2}^{b}\right)\right] U_{d c} / 4\right.
$$

Output voltage of the inverter is given by:

$$
\left(\begin{array}{l}
V_{1} \\
V_{2} \\
V_{3}
\end{array}\right)=\frac{1}{3}\left(\begin{array}{ccc}
2 & -1 & -1 \\
-1 & 2 & -1 \\
-1 & -1 & 2
\end{array}\right)\left(\begin{array}{c}
V_{1 O} \\
V_{2 O} \\
V_{3 O}
\end{array}\right)
$$

As indicated in Table 1, each leg of inverter can have five possible switching states, 1,2,3,4 and 5 .

Table 1. Diode clamped inverter voltage levels and switching states

\begin{tabular}{|c|c|c|c|c|c|c|c|c|c|}
\hline \multirow{2}{*}{$\begin{array}{c}\text { Switching } \\
\text { symbol }\end{array}$} & \multicolumn{7}{|c|}{ Switch state } & Voltage \\
\cline { 2 - 9 } & $\mathrm{S}_{\mathrm{k} 1}$ & $\mathrm{~S}_{\mathrm{k} 1}$ & $\mathrm{~S}_{\mathrm{k} 1}$ & $\mathrm{~S}_{\mathrm{k} 1}$ & $\mathrm{~S}_{\mathrm{k} 1}$ & $\mathrm{~S}_{\mathrm{k} 1}$ & $\mathrm{~S}_{\mathrm{k} 1}$ & $\mathrm{~S}_{\mathrm{k} 1}$ & $V_{k a}$ \\
\hline 1 & 1 & 1 & 1 & 1 & 0 & 0 & 0 & 0 & $U_{d c} / 2$ \\
\hline 2 & 0 & 1 & 1 & 1 & 1 & 0 & 0 & 0 & $U_{d c} / 4$ \\
\hline 3 & 0 & 0 & 1 & 1 & 1 & 1 & 0 & 0 & 0 \\
\hline 4 & 0 & 0 & 0 & 1 & 1 & 1 & 1 & 0 & $-U_{d c} / 4$ \\
\hline 5 & 0 & 0 & 0 & 0 & 1 & 1 & 1 & 1 & $-U_{d c} / 2$ \\
\hline
\end{tabular}

\section{Control of Wind Energy Conversion System}

\section{III.1. MPPT With fuzzy logic control}

The goal of the (MPPT) strategy is to pick up the maximum power from the wind; given by:

$$
P_{m}=0.5 \rho S C_{p}^{o p t}\left(\lambda_{o p t}, \beta\right) V^{3}
$$

The MPPT controls the speed of the rotor by controlling the torque generator according to the optimal tip speed ratio $\lambda_{\text {opt }}$ by imposing on the electromagnetic motor torque to be equal to its optimal reference value, [1]:

$$
T_{e m}=T_{\text {em-ref }}
$$

Usually the wind turbine characteristic is unknown, an operational research based on fuzzy logic is proposed, rules of behavior to keep in order converging to the optimal point, are relatively easy to establish. These rules are based on the variation of the wind power $(\triangle P)$ and the rotation speed of the turbine $(\Delta \Omega)$. The structure of a fuzzy control system is made up of the following blocs:

- Fuzzification,

- Knowledge base (Rules),

- Inference engine,

- Defuzzification.

Fig. 5 shows the structure of a fuzzy logic controller.

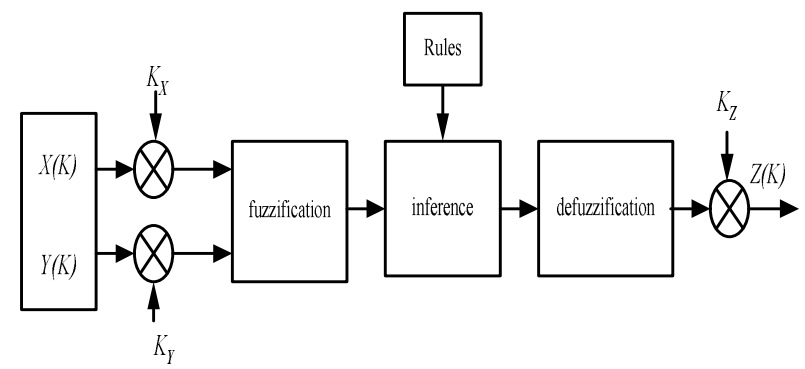

Figure 5. General diagram of a fuzzy controller

To each wind speed, the system has to find the maximal torque, what corresponds in search of the optimal rotation speed. From the existence of linguistic rules, the 
controller by fuzzy logic $(F L C)$ works in the same way as the classic regulator. The block diagram for the power optimization by fuzzy logic is shown in Fig.5. The MPPT device based on the measurement of electrical power variation $(\Delta P)$ and rotation speed $(\Delta \Omega)$ proposes a change $\left(\Delta \Omega^{*}\right)$ of the rotational speed reference of the wind turbine $\left(\Omega^{*}\right)$. The block diagram of the fuzzy logic MPPT is shown in Fig.6.

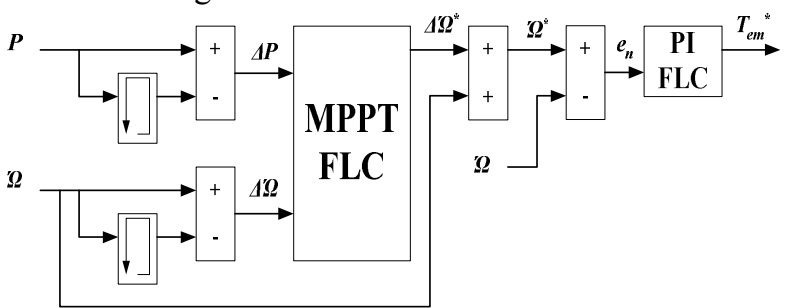

Figure 6. Structure of controller MPPT fuzzy

The rotational speed of the wind turbine is regulated so as to follow the reference speed $\left(\Omega^{*}\right)$ obtained at the output of fuzzy MPPT controller; the output of the speed regulator determines the reference of the electromagnetic torque of the machine. The control rules are established. These ones link the output with the inputs. Each of both linguistic inputs of the fuzzy MPPT controller possesses seven fuzzy sets, which gives a set of forty-nine rules. These ones can be represented by the inference matrix (Table 2).

Table 2. Rules generated for the fuzzy MPPT

\begin{tabular}{|c|c|c|c|c|c|c|c|}
\hline$\Delta \Omega / \Delta P$ & $N B$ & $N M$ & $N S$ & $Z$ & $P S$ & $P M$ & $P B$ \\
\hline$N B$ & $P B$ & $P N$ & $P M$ & $Z$ & $N M$ & $N B$ & $N B$ \\
\hline$N M$ & $P B$ & $P M$ & $P S$ & $Z$ & $N S$ & $N M$ & $N B$ \\
\hline$N S$ & $P M$ & $P S$ & $P S$ & $Z$ & $N S$ & $N S$ & $N M$ \\
\hline$Z$ & $N B$ & $N M$ & $N S$ & $Z$ & $P S$ & $P M$ & $P B$ \\
\hline$P S$ & $N M$ & $N S$ & $N S$ & $Z$ & $P S$ & $P S$ & $P M$ \\
\hline$P M$ & $N B$ & $N M$ & $N S$ & $Z$ & $P S$ & $P M$ & $P B$ \\
\hline$P B$ & $N B$ & $N B$ & $N S$ & $Z$ & $P M$ & $P B$ & $P B$ \\
\hline
\end{tabular}

Each of both linguistic inputs of the fuzzy PI controller possesses five fuzzy sets, which gives a set of twenty five rules. These ones can be represented by the inference matrix (Table 3).

\begin{tabular}{|c|c|c|c|c|c|}
\hline$\Delta e_{n} / e_{n}$ & $N B$ & $N S$ & $Z$ & $P S$ & $P B$ \\
\hline$N B$ & $N B$ & $N S$ & $N S$ & $Z E$ & $Z E$ \\
\hline$N S$ & $N B$ & $N S$ & $N S$ & $Z E$ & $P S$ \\
\hline$Z$ & $N S$ & $N S$ & $Z$ & $P S$ & $P S$ \\
\hline$P S$ & $N S$ & $Z$ & $P S$ & $P S$ & $P B$ \\
\hline$P B$ & $Z$ & $Z$ & $P S$ & $P S$ & $P B$ \\
\hline \multicolumn{7}{|c|}{ Table 3. Rules gerated for the fuzzy PI }
\end{tabular}

This control has two aims: control of battery bank system such illustrated in Fig. 7 and regulation of the $D C$ link capacitor using a corrector who provides the reference current to introduce in the $D C$ link capacitor. The battery is connected to the $D C$-Link via buck-boost chopper. The schematic of the battery converter control is shown in Fig. 7. The power output of the four wind turbines is controlled by supervision system controls by sending reference power for each of the four control unit on the input side such as:

$$
P_{\text {refi }}=\frac{P_{\text {gref }}}{8}-P_{\text {windi }}
$$

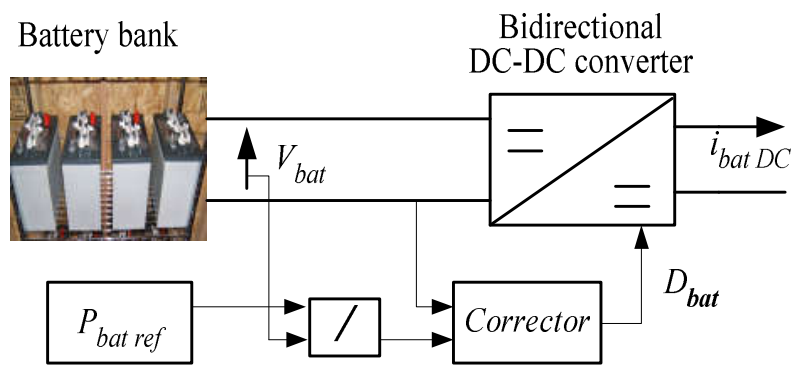

Figure 7. Battery bank storage control

The battery power reference is produced by the supervisory system. The corrector adjusts the current $i_{\text {bat }}$ in the aim to track the reference $i_{\text {bat ref, }}$, with an objective of charging or discharging the battery depending to the need. Fig. 8 shows flow chart of operation of storage battery system.

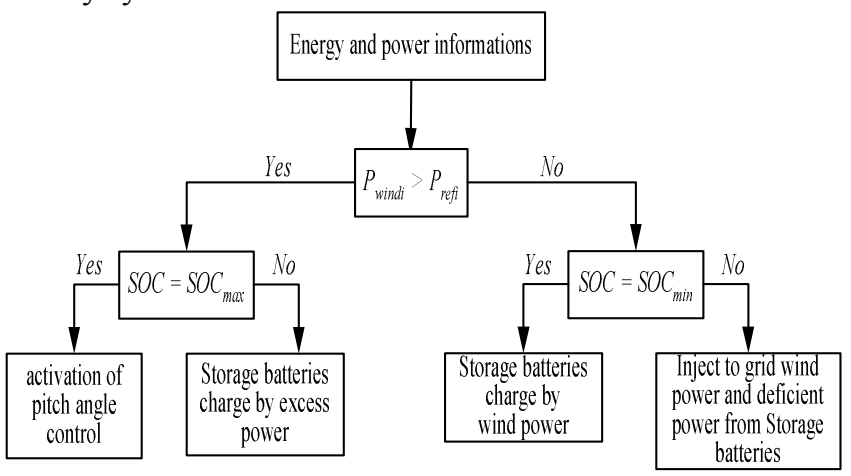

Figure 8. Operation of storage battery

\section{III.3. SVPWM technique for five-level inverter}

One of the most known control approach for multilevel inverters is known as SVPWM, which directly applying the control of the variable provided by the control system and identifies each commutation vector as a point in the complex area of $(\alpha, \beta)$. Studies have shown that the use of SVPWM gives us better results than Sinusoidal $P W M$ schemes concerning harmonic elimination and fundamental voltage ratios. In addition to 
this, the maximum peak value of the output voltage is $15 \%$ higher than triangular carrier-based modulation techniques [18]. Five-level NPC inverter has 125 switching states as shown in Fig. 9. Each phase arm of inverter consists of eight switching element and has five different switching states that are $1,2,3,4,5$ representing positive big, positive small, zero, negative small and negative big switching sequences.

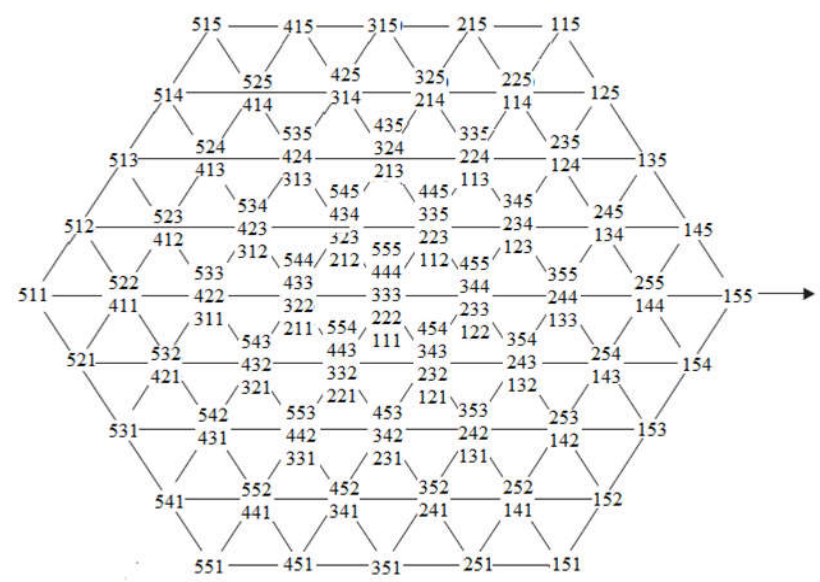

Figure 9. Five-level space vector diagram

In this paper, a new technique is proposed in which the five-level hexagon is subdivided into six smaller threelevel hexagons, and each three-level hexagons is subdivided into six smaller two-level hexagons as it can be seen in Fig.10. The idea is to find in which two level hexagon is located the reference vector to apply the $S V P W M$ for the two-level inverter, and that starting with determining in which three level hexagon the reference vector is located, then subtracts the reference voltage vector from the central vector that connects the center of the five levels hexagon to the center of the hexagon with three levels. New three-level reference vector is created. Repeat the same thing between three level hexagon and two level hexagon to get new two-level reference vector, and finally apply two level SVPWM.

- $\quad$ First simplification: knowing the location of a reference voltage vector, a three level hexagon is selected among the six small hexagons which constitute the five levels space vector diagram. each hexagon is identified by the angle $\theta$ such as:

$$
\left\{\begin{array}{l}
\text { iif } \frac{11 \pi}{6} \leq \theta<\frac{\pi}{6} \\
\text { if } \frac{\pi}{6} \leq \theta<\frac{\pi}{2} \\
\text { 3if } \frac{\pi}{2} \leq \theta<\frac{5 \pi}{6} \\
\text { 4if } \frac{5 \pi}{6} \leq \theta<\frac{7 \pi}{6} \\
\text { 5if } \frac{7 \pi}{6} \leq \theta<\frac{3 \pi}{2} \\
\text { iif } \frac{3 \pi}{2} \leq \theta<\frac{11 \pi}{6}
\end{array}\right.
$$

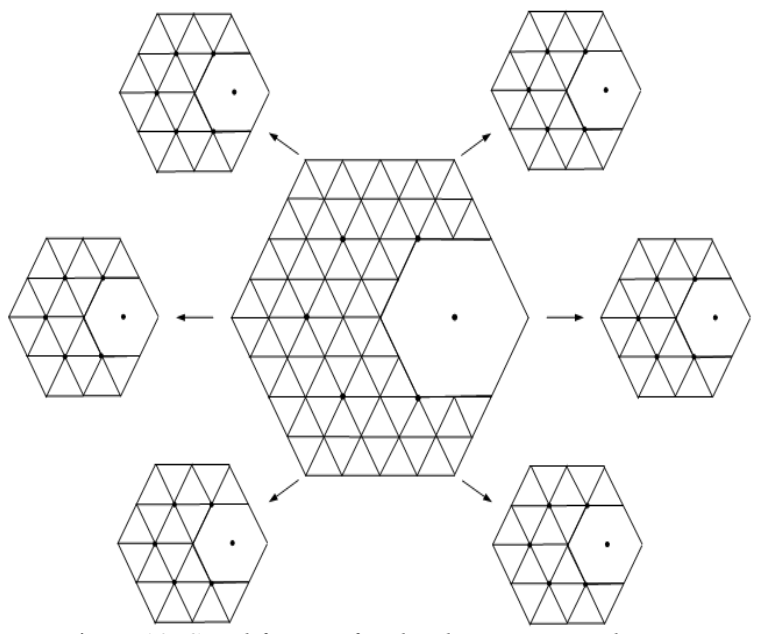

Figure 10. Simplification five-level space vector diagram

After having selected a hexagon, the new reference vector $V_{s}^{* \prime}$ is calculated as follows (Table 4)

Table 4. First correction of reference voltage vector
\begin{tabular}{|c|c|c|}
\hline Hexagon & $V_{\alpha}{ }^{*}$, & $V_{\beta}{ }^{*}$, \\
\hline 1 & $V_{\alpha}{ }^{*}-1 / 2$ & $V_{\beta}{ }^{*}$ \\
\hline 2 & $V_{\alpha}{ }^{*}-1 / 4$ & $V_{\beta}{ }^{*}-\sqrt{3} / 4$ \\
\hline 3 & $V_{\alpha}{ }^{*}+1 / 4$ & $V_{\beta}{ }^{*}-\sqrt{3} / 4$ \\
\hline 4 & $V_{\alpha}{ }^{*}+1 / 2$ & $V_{\beta}{ }^{*}$ \\
\hline 5 & $V_{\alpha}{ }^{*}-1 / 4$ & $V_{\beta}{ }^{*}+\sqrt{3} / 4$ \\
\hline 6 & $V_{\alpha}{ }^{*}+1 / 4$ & $V_{\beta}{ }^{*}+\sqrt{3} / 4$ \\
\hline
\end{tabular}

- Second simplification: Having the selected three levels hexagon and the location of the new vector, one hexagon is selected among the six small hexagons constituting this three level diagram. Computing of the new reference $V_{s}^{*}$ is made. Table.5 gives the components $\alpha$ and $\beta$ of the reference voltage $V_{s}{ }^{*}$."

Table 5. Second correction of reference voltage vector
\begin{tabular}{|c|c|c|}
\hline Hexagon & $V_{\alpha}{ }^{*}$, & $V_{\beta}{ }^{*}$, \\
\hline 1 & $V_{\alpha}{ }^{*}-1 / 4$ & $V_{\beta}{ }^{*}$, \\
\hline 2 & $V_{\alpha}{ }^{*},-1 / 8$ & $V_{\beta}{ }^{*,}-\sqrt{3} / 8$ \\
\hline 3 & $V_{\alpha}{ }^{*}+1 / 8$ & $V_{\beta}{ }^{*},-\sqrt{3} / 8$ \\
\hline 4 & $V_{\alpha}{ }^{*}+1 / 4$ & $V_{\beta}{ }^{*}$, \\
\hline 5 & $V_{\alpha}{ }^{*}-1 / 8$ & $V_{\beta}{ }^{*}{ }^{+}+\sqrt{3} / 8$ \\
\hline 6 & $V_{\alpha}{ }^{*}+1 / 8$ & $V_{\beta}{ }^{*}+\sqrt{3} / 8$ \\
\hline
\end{tabular}

When the new reference voltage $V_{s}^{* \prime}$ and the corresponding hexagon are fixed; the traditional two level space vector Modulation technique can be used. Fig. 11 show the output voltage of the first phase of the inverter and the spectral analysis it shows that the use of SVPWM eliminates harmonic. 


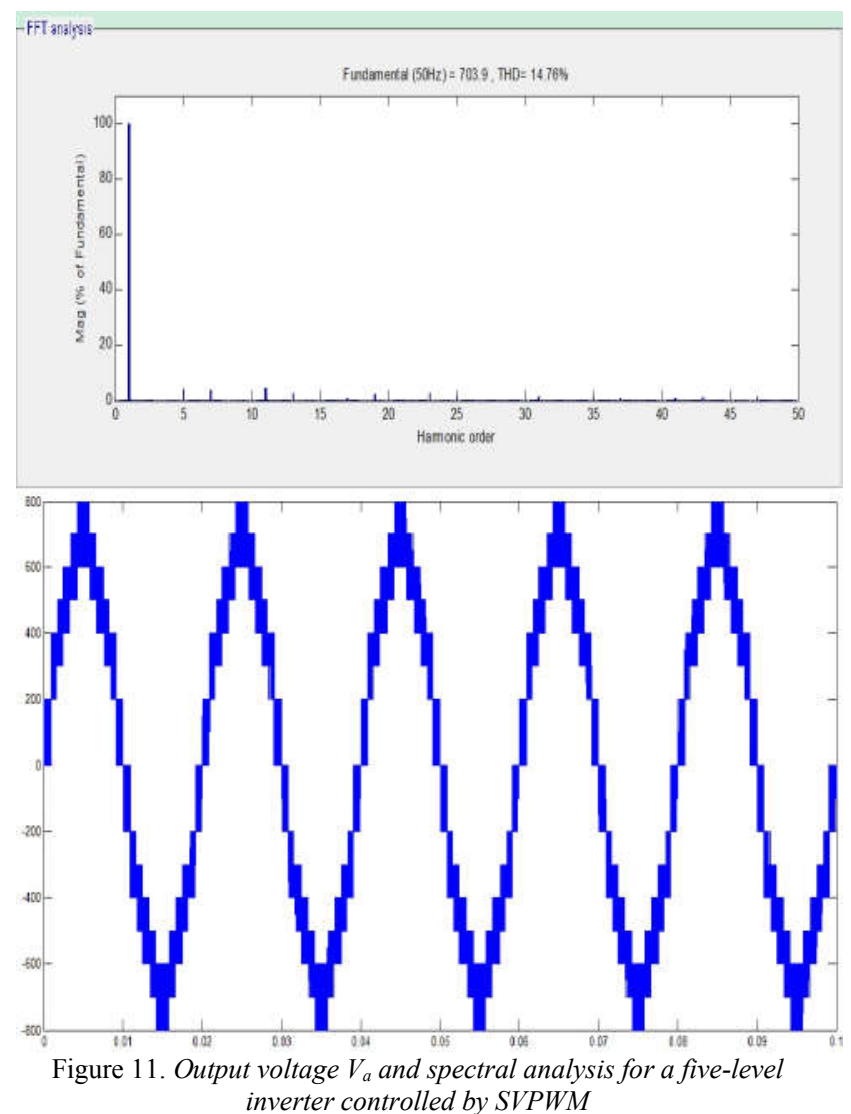

III.4. Control of the grid side

Our system must (PMSG/battery bank) inject sinusoidal currents (amplitude and frequency) same to those of the network with the aim to generate the PMSG/battery bank active power to the grid. The active and reactive powers are given using components of grid voltage current $\left(V_{g d} i_{g d} V_{g q}\right.$ and $\left.i_{g q}\right)$ by:

$$
\left\{\begin{array}{l}
P_{g}=V_{g d} i_{g d}+V_{g q} i_{g q} \\
Q_{g}=V_{g d} i_{g q}-V_{g q} i_{g d}
\end{array}\right.
$$

By controlling $\mathrm{i}_{\mathrm{gd}}$ and $\mathrm{i}_{\mathrm{gq}}$, references for active and reactive power can be obtained $\left(P_{\text {gref }}\right.$ and $\left.Q_{\text {gref }}\right)$ :

$$
\left\{\begin{array}{l}
i_{g q r e f}=\frac{P_{g r e f} V_{g q}-Q_{g r e f} V_{g d}}{V_{g d}^{2}+V^{2}{ }_{g q}} \\
i_{g d r e f}=\frac{P_{g r e f} V_{g d}-Q_{g r e f} V_{g q}}{V_{g d}^{2}+V^{2}{ }_{g q}}
\end{array}\right.
$$

Fig.12 shows us the diagram of the grid side control.

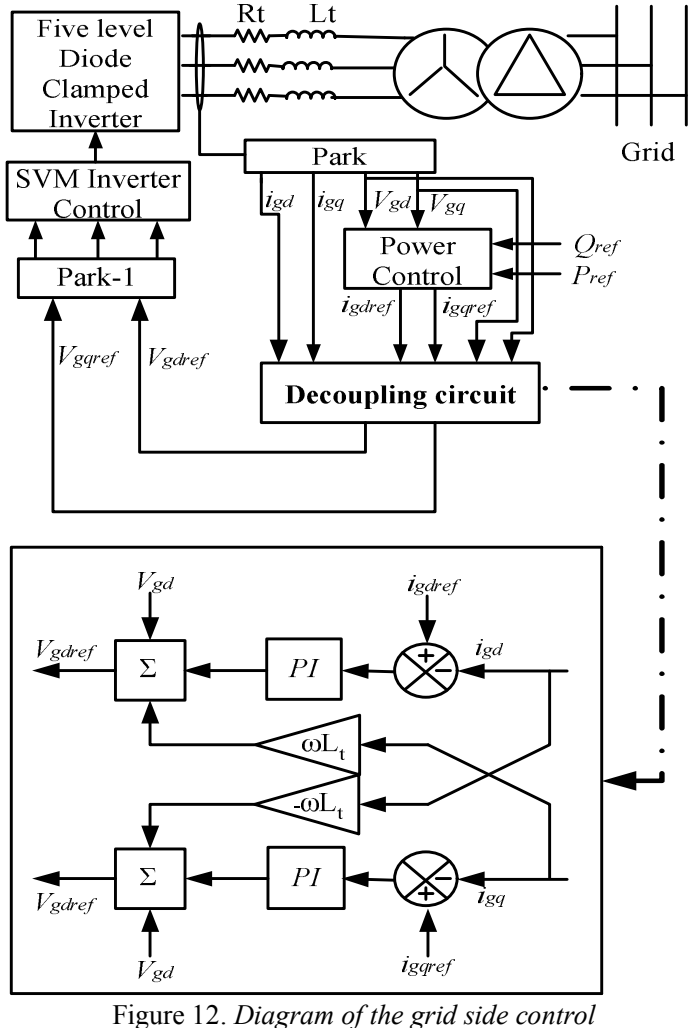

\section{Simulation Results of Global Wind Turbine System}

In this section, global wind turbine system is simulated using MATLAB-SIMULINK, variable wind profile is taken for each turbine as shown in Fig.13. Fig. 14 shows the rotor speeds they have the same allure whereas wind speed which proves a good tracking of our MPPT.

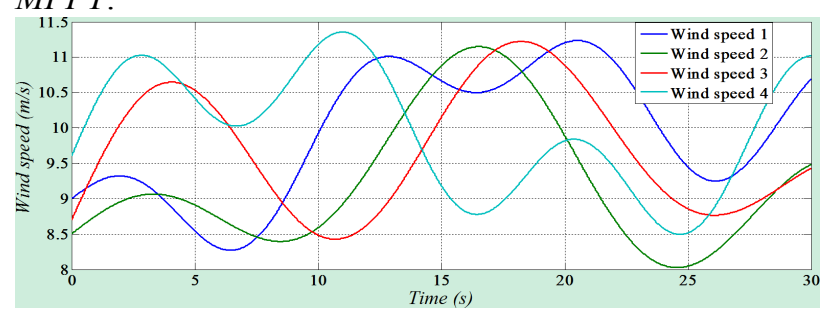

Figure 13. Wind speed profile for each turbine

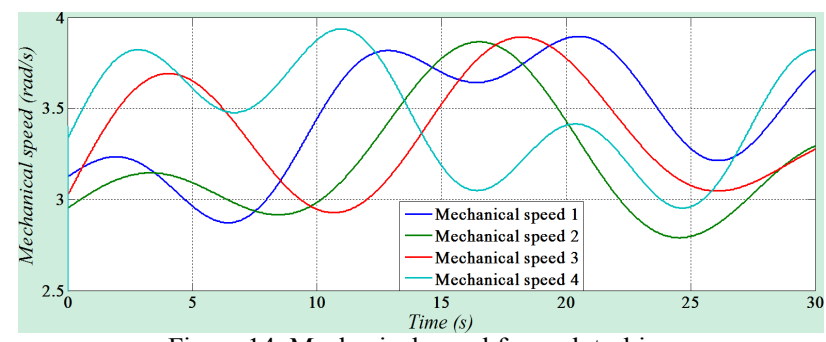

Figure 14. Mechanical speed for each turbine

The generator power output is the sum of the four wind generators powers like shown in Fig.15, negative values to say that power is supplied. 


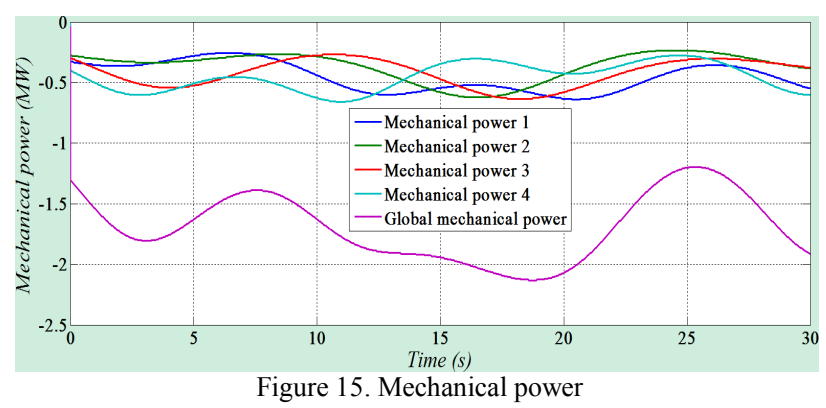

Results simulations show the contribution of storage in grid connected systems. The strategy adopted allows controlling the level of storage of each storage unit when the wind productions are different and compensate the fluctuations of the wind power as illustrated in Figs. 1617.

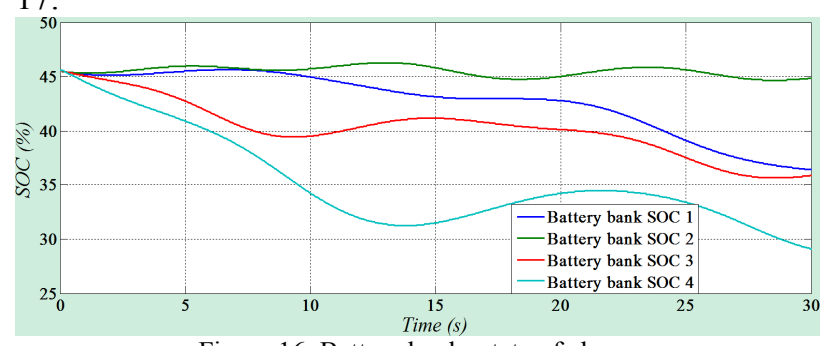

Figure 16. Battery banks state of charge

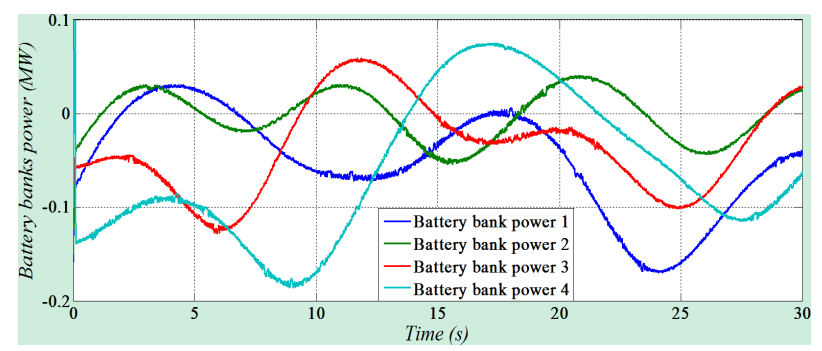

Figure 17. Battery banks power

With battery storage units, we can balance the $D C$ bus as shown in Fig. 18.

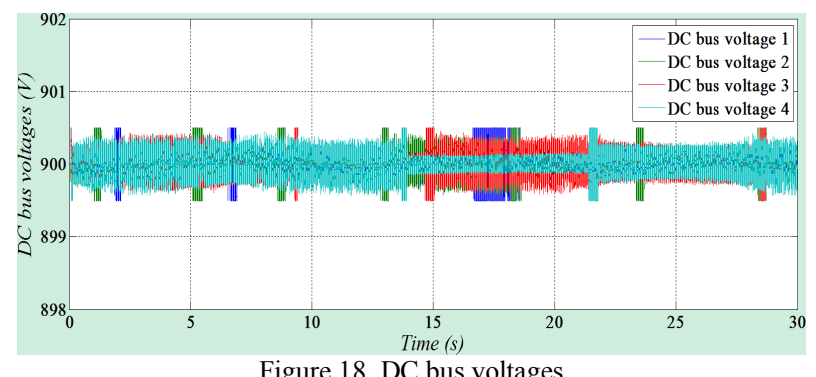

Reactive power is kept at zero (unity power factor) after charging the capacitor Fig.20, Also, the results show that the connection of multiple wind turbines using a single multilevel inverter can inject more power to grid as shown in figs. 19 and 20.
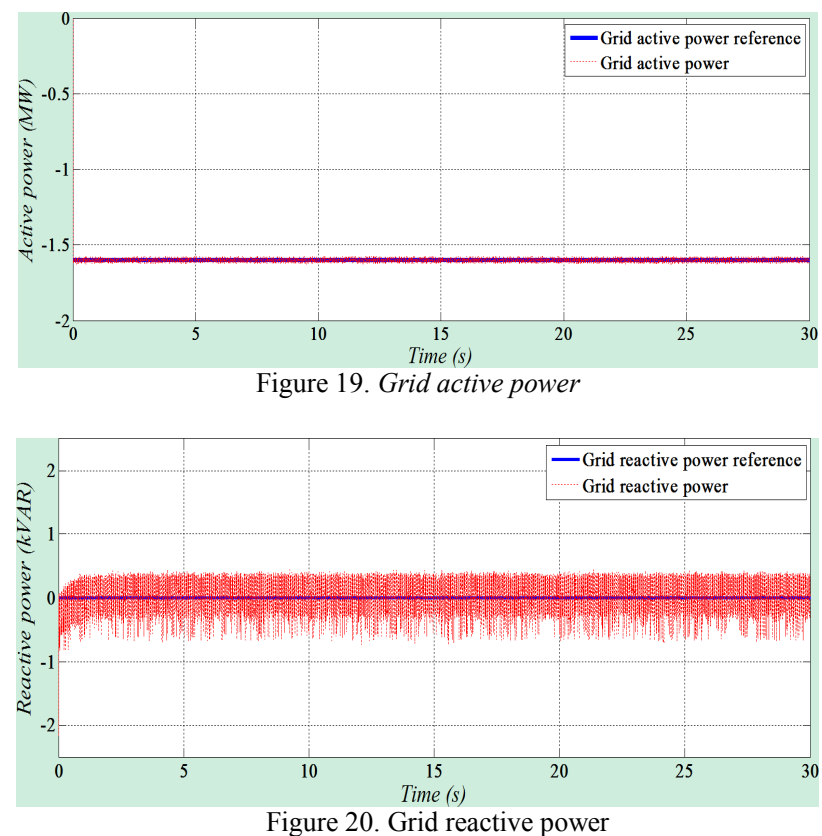

The injected currents are sinusoidal with a constant frequency $(50 \mathrm{~Hz})$ and have a good quality Figs. 21 and 22, The results demonstrate the effectiveness of the inverter control by the simplified space vector modulation.

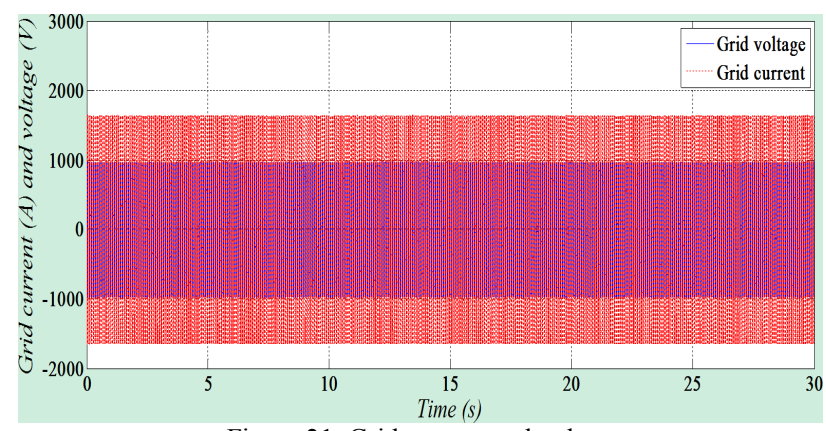

Figure 21. Grid current and voltage

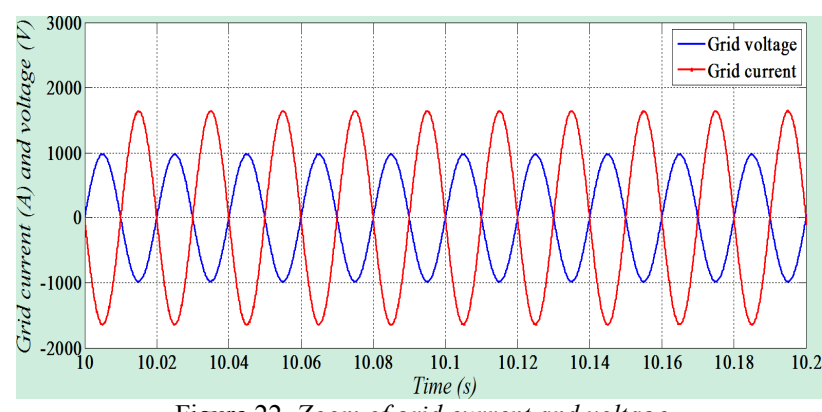

Figure 22. Zoom of grid current and voltage

\section{Conclusion}

This paper proposed the study and the fuzzy logic control of variable speed wind battery storage grid connected system, a wind energy conversion system based on $P M S G$ was proposed, the wind turbine system has been modeled In addition, in order to maximize the 
exploited power from the wind fuzzy logic $M P P T$ control is applied which is most appropriate when there is a lack of information on the characteristic $C_{p}(\lambda, \beta)$ of the turbine, it is a simple and good control method with satisfactory dynamic performance. The PMSG was controlled by vector control; it gave good dynamic performances according to the wind speed variation. the use of a five level $D C I$ with it's simplified space vector modulation as a grid interface gives a good results in term of $T H D$ and power quality, also, the aim was in this work to inject to the grid a fixed power with a variable wind speed, Furthermore, the applied control strategies can benefit a high efficiency, especially by using the $P M S G$. The validity of the studied wind turbine system has been verified by simulation results using Matlab Simulink.

\section{References}

[1] Samira Chekkal, Narimen Aouzellag Lahaçani, Djamal Aouzellag, Kaci Ghedamsi. Fuzzy logic control strategy of wind generator based on the dual-stator induction generator. Electrical Power and Energy Systems, 59, 2014, pp. 166-175.

[2] Chih-Ming Hong, Chiung-Hsing Chen, Chia-Sheng Tu. "Maximum power point tracking-based control algorithm for PMSG wind generation system without mechanical sensors". Energy Conversion and Management, 69, 2013, pp. 58-67.

[3] Abdeldjalil Dahbi, Mabrouk Hachemi, Nasreddine NaitSaid, Mohamed-Said Nait-Said. Realization and control of a wind turbine connected to the grid by using PMSG. Energy Conversion and Management, 84, 2014, pp. 346353.

[4] Ali M. Eltamaly, Hassan M. Farh. "Maximum power extraction from wind energy system based on fuzzy logic control" Electric Power Systems Research, 97, 2013, pp. 144-150.

[5] M. Seixas, R. Melício, V.M.F. Mendes. "Fifth harmonic and sag impact on PMSG wind turbines with a balancing new strategy for capacitor voltages". Energy Conversion and Management, 79, 2014, pp. 721-730.

[6] Gonzalez LG, Figueres E, Garcera G, Carranza O. Maximum-power-point tracking with reduced mechanical stress applied to wind-energy-conversion systems. Appl Energy, 87, 2010, pp. 2304-2312.

[7] Tomonobu S, Yasutaka O, Yasuaki K, Motoki T, Atsushi Y, Endusa BM, et al. Sensorless maximum power point tracking control for wind generation system with squirrel cage induction generator. Renew Energy, 34, 2009, pp. 994-999.

[8] M.A. Abdullaha, A.H.M. Yatima, C.W. Tana, R. Saidurb. A review of maximum power point tracking algorithms for wind energy systems. Renewable and Sustainable Energy Reviews, 16, 2012, pp. 3220-3227.

[9] Mohammed Yekini Suberu, Mohd Wazir Mustafa, Nouruddeen Bashir. Energy storage systems for renewable energy power sector integration and mitigation of intermittency. Renewable and Sustainable Energy Reviews, 35, 2014, pp. 499-514.

[10] Evans A, Strezov V, Evans TJ. Assessment of utility energy storage options for increased renewable energy penetration. Renew Sustain Energy Rev, 16, 2012, pp. 4141-4147.

[11] AM Howlader, N Urasaki, A Yona, T Senjyu, AY Saber. A review of output power smoothing methods for wind energy conversion systems. Renew Sustain Energy Rev, 26, 2013, pp. 135-146.

[12] M. Maamir, A. Betka, H. Aboub. Modeling and Simulation of Energy Management Hybrid Sources System composed of Solar-PV and Battery. International Journal of Energetica (IJECA), 1, 2016, pp. 12-19.

[13] Rahim AHMA, Nowicki EP. Supercapacitor energy storage system for fault ride through of a DFIG wind generation system. Energy Convers Manage, 59, 2012, pp. $96-102$.

[14] H Xuesong, S Caixin, L Ren, L Yong. An active power smoothing strategy for direct-driven permanent magnet synchronous generator based wind turbine using flywheel energy storage. Automat Electr Pow Syst. 2010

[15] T. Kinjo, T. Senjyu, N. Urasaki, H. Fujita. Terminalvoltage and output-power regulation of wind-turbine generator by series and parallel compensation using SMES. IET Proc-Gener Trans Distrib, 153, 2006, pp. 276-282.

[16] FD. Gonzalez, A. Sumper, OG. Bellmunt, RV. Robles. A review of energy storage technologies for wind power applications". Renew Sustain Energy Rev, 16, 2012, pp. 2154-2171.

[17] M. Khalid, A.V. Savkin. Minimization and control of battery energy storage for wind power smoothing: Aggregated, distributed and semi-distributed storage. Renewable Energy, 64, 2014, pp. 105-112.

[18] I. Colak, , E. Kabalci, , R. Bayindir. Review of multilevel voltage source inverter topologies and control schemes. Energy conversion and Management, 52, 2011, pp. 1114 1128.

[19] Ravi, A., Manoharan, P.S, \& Vijay Anand, J. Modeling and simulation of three phase multilevel inverter for gird connected photovoltaic systems. Solar Energy, 85, 2011, pp. 2811-2818.

[20] Al-Othman, AK., \& Abdelhamid, TH. Elimination of harmonics in multilevel inverters with non-equal $\mathrm{dc}$ sources using PSO. J Energy Convers Manage, 50, 2009, pp. 756-765.

[21] Rahim, N., Selvaraj, J., \& Krismadinata, C. Five-level inverter with dual reference modulation technique for grid-connected PV system .Renewable Energy, 35 (2010), pp. $712-720$.

[22] Andreas Poullikkas. A comparative overview of largescale battery systems for electricity storage. Renewable and Sustainable Energy Reviews, 27, 2013, pp. 778-788.

[23] Bayar T. Batteries for energy storage: new developments promise grid flexibility and stability. Renewable Energy World magazine 2011

[24] Wichert Benjamin. Control of photovoltaic diesel hybrid energy systems. Ph.D. thesis of the Curtin University of Technology, 2000. 